\title{
FAKTOR-FAKTOR YANG BERHUBUNGAN DENGAN KEPATUHAN BIDAN DALAM PENERAPAN PARTOGRAF
}

\author{
Iis*
}

\begin{abstract}
ABSTRAK
Partograf dapat meningkatan mutu dan keteraturan pemantauan janin dan ibu selama persalinan serta dapat membantu menemukan adanya masalah pada janin atau ibu. Kepatuhan bidan dalam penerapan partograf adalah Kepatuhan prosedur yang dilakukan untuk membuat alat bantu pemantauan kemajuan persalinan dan untuk membuat keputusan klinik. Tujuan dari penelitian ini adalah untuk mengetahui faktor-faktor yang berhubungan dengan kepatuhan bidan dalam penerapan partograf. Penelitian ini menggunakan Survei analitik dengan pendekatan Cross sectional. Batasan sampel dalam penelitian ini menggunakan kriteria inklusi yaitu bidan yang bekerja di Puskesmas PONED wilayah kabupaten sukabumi dan mau mengisi inform consent yaitu sebanyak 46 orang. Analisa yang digunakan dalam penelitian ini adalah analisa univariat dan bivariat dengan menggunakan Uji Statistik Chi-Square $\left(\mathrm{X}^{2}\right)$. Hasil penelitian sebagian besar bidan yang tidak patuh dalam penerapan partograf sebesar 54,3\%. Setelah dilakukan Uji Bivariat maka diperoleh hasil bahwa variabel yang bermakna adalah untuk tingkat pengetahuan P-Value 0,021, untuk tingkat pendidikan P-Value 0,016, untuk tingkat lama bekerja $\mathrm{P}$ Value 0,021 dan untuk pelatihan P-Value 0,004 dan $\mathrm{OR}=7,917$.
\end{abstract}

Kata Kunci : Partograf, Bidan, Kepatuhan

\begin{abstract}
Partographs can improve the quality and regularity of maternal and fetal monitoring during labor and can help find problems in the fetus or the mother. Compliance partograf midwife in the application of the compliance procedure is done to make the tools of monitoring the progress of labor and to make clinical decisions. The aim of this study was to determine the factors associated with adherence midwife in the application partograf. This study uses Analytical Survey with cross sectional approach. Population in this research is all that is in BEONC Bureau of Sukabumi district, sampling in this research use accidental sampling is a midwife who works at the health center PONED Sukabumi district, would fill informed consent and there at the time of the research conducted as many as 46 people. Methods of data collection using primary data using questionnaires. The analysis used in this research is the analysis of univariate and bivariate descriptive analysis using Chi-Square Test Statistics $\left(\mathrm{x}^{2}\right)$. Results of the study most of the midwife who do not comply in the application of partograf 54.3\%. After Test Bivariat the obtained results that the variables that are meaningful to the knowledge level of the P-Value 0.021, to the level of education P-Value 0.016, to the level of long working P-Value 0,021 and for training P-Value 0.004. Based on the research results in the application of partograf compliance midwife for 21 people $(45,7 \%)$.
\end{abstract}

Keywords: Partograph, midwives, compliance 


\section{PENDAHULUAN}

Tingginya kasus kesakitan dan kematian ibu di negara berkembang terutama disebabkan oleh perdarahan pasca persalinan, eklampsia, sepsis dan komplikasi keguguran. Sebagian besar penyebab utama kematian ibu tersebut, sebenarnya dapat dicegah melalui upaya pencegahan yang efektif. Beberapa negara berkembang dan hampir semua negara maju berhasil menurunkan angka kesakitan dan kematian ibu ke tingkat yang sangat rendah. ${ }^{1}$

Organisasi kesehatan dunia (WHO) melakukan pembahasan khusus tentang angka kematian ibu di Asia Tenggara menyumbang hampir sepertiga jumlah kematian ibu dan anak. WHO memperkirakan sebanyak 37 juta kelahiran terjadi dikawasan asia tenggara setiap tahun. Sementara total kematian ibu dan bayi lahir kawasan ini diperkirakan berturut-turut 170 ribu dan 1,3 juta pertahun. ${ }^{2}$

Angka kematian ibu dan bayi di Indonesia berdasarkan Badan Pusat Statistik (BPS) diperoleh AKI tahun 2009 sebesar 228/100.000 kelahiran hidup, AKB sebesar 34/1000 kelahiran hidup. Berdasarkan data dinas kesehatan Jawa barat dari 26.698 kelahiran tahun



Tingginya angka kematian ibu tersebut dapat terjadi pada masa kehamilan, persalinan dan pasca persalinan. Penyebab tingginya kematian ibu disebabkan olek komplikasi obstetric yaitu perdarahan berkisar $40 \%-60 \%$ dari total angka kematian ibu, pre eklampsia atau eklampsia (20\%-30\%) dan infeksi jalan lahir ( 20\%-30\%). Komplikasi obstetrik ini tidak selalu dapat diramalkan sebelumnya dan mungkin saja terjadi pada ibu hamil yang telah diidentifikasi normal. ${ }^{4}$

Kehamilan aterm dengan posisi letak kepala mencakup sekitar $97 \%$ dari semua kehamilan. Sekitar 3\% merupakan kehamilan dengan kedudukan patologis, sehingga akan dirujuk ke pusat pelayanan, dikemukakan Angka Kematian Ibu (AKI) dan Angka Kematian Anak (AKA) sebagian besar mempunyai faktor yang masih dapat dikendalikan. Angka kematian maternal dan Perinatal yang tinggi disebabkan oleh dua hal penting yang memerlukan perhatian khusus, yaitu terjadinya partus terlantar/partus lama. Penyebab utama kematian maternal perinatal dan terlambatnya melakukan rujukan. Pelaksanaan Partograf dirancang untuk persalinan pervaginam dan dapat digunakan di Puskesmas, pertolongan Persalinan bidan swasta, Polindes atau RS Pusat Rujukan. ${ }^{5}$

Penyebab $85 \%$ kematian ibu berada pada saat bersalin, hal ini berkaitan erat dengan kualitas pelayanan yang dilakukan pada saat persalinan. Salah satu upaya untuk memperbaiki status kesehatan ibu saat bersalin yaitu dengan penggunaan partograf sebagai alat bantu untuk membuat keputusan klinik, memantau, mengevaluasi dan menatalaksana persalinan. Partograf dapat digunakan untuk mendeteksi dini masalah dan penyulit dalam persalinan sehingga dapat sesegera mungkin menatalaksana masalah tersebut atau merujuk ibu dalam kondisi optimal. Instrumen ini merupakan salah satu komponen dari pemantauan dan penatalaksanaan proses persalinan secara lengkap. ${ }^{1}$

Jumlah kematian ibu dan bayi di Kabupaten Sukabumi terus mengalami peningkatan. Berdasarkan data dari Dinas Kesehatan Sukabumi pada tahun 2007 jumlah kematian kasus tercatat sebanyak 29 orang. Pada tahun 2008 sebanyak 31 kasus dan selama tahun 2009 tercatat jumlah kematian Ibu sebanyak 49 kasus. Sedangkan untuk jumlah kematian bayi pada tahun 2007 sebanyak 116 kasus, pada tahun 2008 sebanyak 361 kasus dan pada tahun 2009 sebanyak 552 kasus kematian bayi. Menurut data dinas kesehatan kabupaten Sukabumi tahun 2009 dari sampel 170 orang bidan hanya 30\% (51 orang) bidan yang membuat partograf pada saat menolong persalinan. ${ }^{6}$

Puskesmas PONED (Pelayanan Obstetri Neonatal Esensial Dasar) di Kabupaten Sukabumi merupakan salah satu puskesmas yang menangani persalinan, berdasarkan hasil pra survei yang peneliti lakukan pada bulan Februari 2011 didapatkan jumlah bidan yang ada di 
puskesmas PONED sukabumi berjumlah 67 orang. Pada bidan tersebut, sudah mengaplikasikan partograf di lapangan, tapi belum pernah dilakukan penelitian tentang kepatuhan penerapannya. ${ }^{6}$ Tujuan penelitian ini adalah untuk mengetahui faktor-faktor yang berhubungan dengan kepatuhan bidan dalam penerapan partograf pada setiap asuhan persalinan di Puskesmas PONED wilayah Kabupaten Sukabumi Tahun 2011”.

\section{METODE PENELITIAN}

Penelitian ini bersifat deskriptif Analitik yang dilaksanakan dengan desain potong lintang (Cross Sectional) dimana semua variabel independen dan dependent diambil secara bersamaan sehingga tidak dapat menggambarkan hubungan sebab akibat, tetapi hanya dapat menggambarkan adanya suatu hubungan antara dua variabel. ${ }^{7}$ Populasi dalam penelitian ini adalah seluruh bidan yang ada di puskesmas PONED wilayah Kabupaten Sukabumi sebanyak 67 orang. Jumlah sampel dalam penelitian ini sebanyak 46 orang diambil dengamn teknik accidental sampling. Metode pengumpulan data menggunakan observasi dan wawancara dengan instrument kuesioner. Analisis yang digunakan adalah analisis deskriptif dengan menyajikan distribusi frekuensi masing-masing variabel sedangkan analisis bivariat dengan menggunakan uji chi square

\section{HASIL PENELITIAN}

\section{Tingkat Kepatuhan Bidan}

Berdasarkan hasil penelitian didapatkan bahwa paling banyak responden yang tidak patuh dalam penerapan partograf adalah 25 orang $(54,30 \%)$.

\section{Tingkat Pengetahuan Bidan}

Berdasarkan hasil penelitian di dapatkan bahwa Bidan di Puskesmas PONED Wilayah Kabupaten Sukabumi Tahun 2011 paling banyak responden yang memiliki pengetahuan tinggi adalah 31 orang $(67,40 \%)$.

\section{Tingkat Pendidikan Bidan}

Berdasarkan hasil penelitian di dapatkan bahwa tingkat pendidikan bidan di Puskesmas PONED Wilayah Kabupaten Sukabumi Tahun 2011 paling banyak responden berpendidikan DIII Kebidanan yaitu 40 orang $(87,0 \%)$.

\section{Lama Bekerja}

Berdasarkan hasil penelitian di dapatkan bahwa lama bekerja Bidan di Puskesmas PONED Wilayah Kabupaten Sukabumi Tahun 2011 paling banyak lama bekerja responden pada kategori lama yaitu 27 orang $(58,7 \%)$.

\section{Pelatihan Bidan}

Berdasarkan hasil penelitian di dapatkan bahwa pelatihan Bidan di Puskesmas PONED Wilayah Kabupaten Sukabumi Tahun 2011 paling banyak responden yang belum mengikuti pelatihan APN yaitu 25 orang $(54,3 \%)$. 


\section{Hubungan Pengetahuan Bidan dengan Kepatuhan Bidan}

Tabel 1. Hubungan Pengetahuan Bidan dengan Kepatuhan Bidan Dalam Penerapan Partograf pada Setiap Asuhan Persalinan

\begin{tabular}{|c|c|c|c|c|c|c|c|}
\hline \multirow{3}{*}{ Tingkat Pengetahuan Bidan } & \multicolumn{4}{|c|}{ Kepatuhan } & \multirow{2}{*}{\multicolumn{2}{|c|}{ Total }} & \multirow{3}{*}{$\begin{array}{c}P \\
\text { Value }\end{array}$} \\
\hline & \multicolumn{2}{|c|}{ Patuh } & \multicolumn{2}{|c|}{ Tidak Patuh } & & & \\
\hline & $\mathrm{n}$ & $\%$ & $\mathrm{n}$ & $\%$ & $\mathrm{n}$ & $\%$ & \\
\hline Rendah & 11 & 73,3 & 4 & 26,7 & 15 & 100 & \multirow{2}{*}{0,021} \\
\hline Tinggi & 10 & 32,3 & 21 & 67,7 & 31 & 100 & \\
\hline
\end{tabular}

Hasil uji statistik hubungan antara pengetahuan bidan dengan kepatuhan penerapan partograf didapatkan nilai $P$ Value $=0,021<$ alpha $=0,05$ yang berarti ada hubungan yang bermakna antara pengetahuan bidan dengan kepatuhan penerapan partograf dalam penelitian ini.

\section{Hubungan Pendidikan Bidan dengan Kepatuhan Bidan}

Tabel 2. Hubungan Pendidikan Bidan dengan Kepatuhan Bidan Dalam Penerapan Partograf pada Setiap Asuhan Persalinan

\begin{tabular}{|c|c|c|c|c|c|c|c|}
\hline \multirow{3}{*}{ Pendidikan Bidan } & \multicolumn{4}{|c|}{ Kepatuhan } & \multirow{2}{*}{\multicolumn{2}{|c|}{ Total }} & \multirow{3}{*}{$\begin{array}{c}P \\
\text { Value }\end{array}$} \\
\hline & \multicolumn{2}{|c|}{ Patuh } & \multicolumn{2}{|c|}{ Tidak Patuh } & & & \\
\hline & $\mathrm{n}$ & $\%$ & $\mathrm{n}$ & $\%$ & $\mathrm{n}$ & $\%$ & \\
\hline DI Kebidanan & 2 & 100 & 0 & 0 & 2 & 100 & \\
\hline DIII Kebidanan & 15 & 37,5 & 25 & 62,5 & 40 & 100 & \\
\hline DIV Kebidanan & 4 & 100 & 0 & 0 & 4 & 100 & 0,010 \\
\hline Total & 21 & 45,7 & 25 & 54,3 & 46 & 100 & \\
\hline
\end{tabular}

Hasil uji statistik hubungan antara pendidikan bidan dengan kepatuhan penerapan partograf didapatkan nilai $\mathrm{P}$ Value $=0,016<$ alpha $=0,05$ yang berarti ada hubungan yang bermakna antara pendidikan bidan dengan kepatuhan penerapan partograf dalam penelitian ini. 


\section{Hubungan Lama Bekerja Bidan dengan Kepatuhan Bidan}

Tabel 3. Hubungan Lama Bekerja Bidan dengan Kepatuhan Bidan Dalam Penerapan Partograf Pada Setiap Asuhan Persalinan

\begin{tabular}{|c|c|c|c|c|c|c|c|}
\hline \multirow{3}{*}{ Lama Bekerja Bidan } & \multicolumn{4}{|c|}{ Kepatuhan } & \multirow{2}{*}{\multicolumn{2}{|c|}{ Total }} & \multirow{3}{*}{$\begin{array}{c}P \\
\text { Value }\end{array}$} \\
\hline & \multicolumn{2}{|c|}{ Patuh } & \multicolumn{2}{|c|}{ Tidak Patuh } & & & \\
\hline & $\mathrm{n}$ & $\%$ & $\mathrm{n}$ & $\%$ & $\mathrm{n}$ & $\%$ & \\
\hline Baru & 13 & 68,4 & 6 & 31,6 & 19 & 100 & \\
\hline Lama & 8 & 29,6 & 19 & 70,4 & 27 & 100 & 0,021 \\
\hline Total & 21 & 45,7 & 25 & 54,3 & 46 & 100 & \\
\hline
\end{tabular}

Hasil uji statistik hubungan antara lama bekerja bidan dengan kepatuhan penerapan partograf didapatkan nilai PValue $=0,021<$ alpha $=0,05$ yang berarti ada hubungan yang bermakna antara lama bekerja bidan dengan kepatuhan penerapan partograf dalam penelitian ini.

\section{Hubungan Pelatihan APN dengan Kepatuhan bidan Dalam penerapan Partograf}

Tabel 4. Hubungan Pelatihan APN dengan Kepatuhan Bidan Dalam Penerapan Partograf pada Setiap Asuhan Persalinan

\begin{tabular}{|c|c|c|c|c|c|c|c|}
\hline \multirow{3}{*}{ Pelatihan APN } & \multicolumn{4}{|c|}{ Kepatuhan } & & & \multirow{3}{*}{$\begin{array}{c}P \\
\text { Value }\end{array}$} \\
\hline & \multicolumn{2}{|c|}{ Patuh } & \multicolumn{2}{|c|}{$\begin{array}{l}\text { Tidak } \\
\text { Patuh }\end{array}$} & \multicolumn{2}{|c|}{ Total } & \\
\hline & $\mathrm{n}$ & $\%$ & $\mathrm{n}$ & $\%$ & $\mathrm{n}$ & $\%$ & \\
\hline Sudah APN & 15 & 71,4 & 6 & 28,6 & 21 & 100 & \\
\hline Belum APN & 6 & 24,0 & 19 & 76,0 & 25 & 100 & 0,004 \\
\hline Total & 21 & 45,7 & 25 & 54,3 & 46 & 100 & \\
\hline
\end{tabular}

Hasil uji statistik hubungan antara lama bekerja bidan dengan kepatuhan penerapan partograf didapatkan nilai $P$ Value $=0,004<$ alpha $=0,05$ yang berarti ada hubungan yang bermakna antara pelatihan dengan kepatuhan penerapan partograf dalam penelitian ini.

\section{PEMBAHASAN}

\section{Kepatuhan Bidan dalam Penerapan Partograf}

Berdasarkan hasil penelitian yang dilakukan kepatuhan bidan dalam penerapan partograf di Wilayah Kabupaten Sukabumi Tahun 2011 hasilnya adalah ditemukan kasus kepatuhan bidan dalam penerapan partograf sebesar tidak patuh lebih banyak yaitu 54,3\%. Hal ini mungkin disebabkan karena aplikasi bidan dalam penerapan partograf masih kurang. Perilaku manusia dilihat dalam konteksnya, prilaku manusia bukan hanya respon pada stimulant, tetapi produk berbagai gaya yang mempengaruhinya secara spontan. Sedangkan prilaku yang belum konkrit (covert behavior) adalah bentuk yang tidak dapat diobservasi 
secara langsung berupa pengetahuan, tanggapan,sikap dan tanggapan sedangkan prilaku yang nyata (overt behavior) adalah yang dapat diobservasi secara langsung yaitu berupa tindakan prilaku nyata dalam bentuk tindakan yang diobservasi (diteliti). Dalam hal ini termasuk dalam kepatuhan penerapan partograf. ${ }^{8}$

\section{Hubungan Pengetahuan Bidan terhadap Penerapan Partograf}

Responden yang memiliki tingkat pengetahuan rendah yang patuh sebesar $73,3 \%$ sedangkan responden yang memiliki tingkat pengetahuan tinggi yang patuh sebesar $32,3 \%$. Hasil uji statistik hubungan antara pengetahuan bidan dengan kepatuhan bidan dalam penerapan partograf didapatkan nilai $\mathrm{P}$-Value $0,021<0,05$ karena $\mathrm{P}$-Value $<$ alpha maka $\mathrm{Ha}$ diterima atau $\mathrm{H}_{0}$ ditolak artinya terdapat hubungan yang signifikan antara pengetahuan dengan kepatuhan.

Bidan yang memiliki pengetahuan rendah lebih patuh dibandingkan bidan yang memiliki pengetahuan tinggi,hal ini mungkin disebabkan karena bidan yang memiliki pengetahuan tinggi menurut taxonomy bloom bidan tersebut hanya ada pada tingkatan tahu dan memahami saja belum masuk dalam tahap tingkatan aplikasi yaitu kemampuan untuk menggunakan materi yang telah dipelajari pada situasi yang sebenarnya. ${ }^{8}$

\section{Hubungan Pendidikan Bidan dengan Kepatuhan Penerapan Partograf}

Responden yang memiliki tingkat pendidikan DIV Kebidanan/S1 kesehatan lain dan DI Kebidanan yang patuh sebesar $100 \%$ sedangkan responden yang memiliki tingkat pendidikan DIII Kebidanan yang patuh sebesar 37,5\% . Hasil uji statistik hubungan antara pendidikan bidan dengan kepatuhan bidan dalam penerapan partograf didapatkan nilai $P$-Value 0,016 $<0,05$ karena $P$-Value $<$ alpha maka $\mathrm{H}_{\mathrm{a}}$ diterima atau $\mathrm{H}_{0}$ ditolak artinya terdapat hubungan yang signifikan antara tingkat pendidikan dengan kepatuhan.

Pendidikan seorang bidan merupakan penuntun untuk berbuat dan mengisi kehidupannya yang dapat digunakan untuk mendapatkan informasi sehingga dapat meningkatkan kualitas hidup. Semakin tinggi tingkat pendidikan seseorang, makin mudah menerima informasi. ${ }^{8}$

\section{Hubungan Lama Bekerja Bidan terhadap Penerapan Partograf}

Responden yang memiliki kategori lama bekerja lama yang tidak patuh sebesar $70,4 \%$ sedangkan responden yang memiliki kategori lama bekerja baru yang tidak patuh sebesar $31,6 \%$. Hasil uji statistik hubungan antara lama bekerja bidan dengan kepatuhan bidan dalam penerapan partograf didapatkan nilai $\mathrm{P}$-Value 0,021 < 0,05 karena $\mathrm{P}$-Value < alpha maka Ha diterima atau $\mathrm{H}_{0}$ ditolak artinya terdapat hubungan yang signifikan antara lama bekerja bidan dengan kepatuhan. Masa kerja adalah rentang waktu yang telah ditempuh oleh seorang bidan dalam melaksanakan tugasnya, selama waktu itulah banyak pengalaman dan pelajaran yang dijumpai sehingga akan berpengaruh terhadap kinerja termasuk dalam kepatuhan penggunaan partograf. $^{8}$

\section{Hubungan Pelatihan Bidan terhadap Penerapan Partograf}

Responden yang memiliki yang belum mengikuti pelatihan APN yang tidak patuh sebesar $76 \%$ sedangkan responden yang sudah mengikuti pelatihan APN yang tidak patuh sebesar 28,6\%. Hasil uji statistik hubungan antara lama bekerja bidan dengan kepatuhan bidan dalam penerapan partograf didapatkan nilai PValue 0,004 < 0,05 karena PValue < alpha maka $\mathrm{H}_{0}$ ditolak atau Ha diterima artinya terdapat hubungan yang signifikan antara pelatihan APN dengan kepatuhan penerapan partograf. 
Tujuan dari APN atau asuhan persalinan normal adalah menjaga kelangsungan hidup untuk memberikan derajat kesehatan yang tinggi bagi ibu dan bayinya, melalui upaya yang terintregasi dan lengkap tetapi dengan intervensi yang seminimal mungkin agar prinsip keamanan dan kualitas pelayanan terjaga pada tingkat yang diinginkan. ${ }^{9}$

\section{SIMPULAN}

1. Kepatuhan Bidan dalam penerapan partograf lebih besar tidak patuh $(54,3 \%)$.

2. Hasil uji statistik didapatkan terdapat hubungan yang signifikan antara tingkat pengetahuan dengan Kepatuhan

3. Terdapat hubungan yang signifikan antara tingkat pendidikan dengan kepatuhan.

4. Terdapat hubungan yang signifikan antara lama bekerja dengan kepatuhan

5. Terdapat hubungan yang signifikan antara pelatihan dengan kepatuhan.

\section{SARAN}

1. Dinas Kesehatan

Agar meningkatkan Jumlah Pelatihan bagi bidan yang berhubungan dengan keterampilan bidan misalnya APN secara merata dan melakukan Monitoring dan Evaluasi (Monev) pada puskesmas secara berkala terutama tentang kepatuhan penerapan partograf.

2. Puskesmas

Agar kepala puskesmas memantau bidan koordinator untuk melakukan bimbingan dan evaluasi terhadap bidan di puskesmas tersebut tentang kepatuhan terhadap penerapan partograf pada setiap asuhan persalinan secara berkala.

3. Bagi bidan

Agar bidan dapat meningkatkan ilmu pengetahuan dan keterampilannya dan dapat mengaplikasikan partograf dilapangan sesuai dengan protap yang sudah ada.

\section{DAFTAR PUSTAKA}

1. Depkes RI. Buku Acuan Asuhan Persalinan Normal. Jakarta: Depkes RI; 2008

2. Anonim, Angka Kematian Ibu. [di akses tanggal 18 Juli 2011]. Diunduh dari: http: akuindonesia.wo.id.press.com

3. Anonim, Angka Kematian Ibu dan Bayi.[di akses tanggal 18 Juli 2011]. Diunduh dari: http://DinkesJabar.go.id.

4. Depkes RI. Standar Pelayanan Kebidanan jilid I. Jakarta: Depkes RI; 2005

5. Manuaba. Ilmu kebidanan penyakit kandungan dan keluarga berencana untuk pendidikan bidan. Jakarta: EGC; 1998

6. Dinas Kesehatan Kab. Sukabumi. Profil Dinas Kesehatan Kabupaten Sukabumi Tahun 2010: Sukabumi; 2011

7. Notoatmodjo,Soekidjo. Metodologi penelitian kesehatan. Jakarta: Rineka Cipta; 2010

8. Notoatmodjo, Soekidjo. Promosi kesehatan, teori dan aplikasi. Edisi Revisi. Jakarta: PT. Rineka Cipta; 2010

9. Anonim, Asuhan persalinan normal.[di akses tanggal 12 Maret 2011]. Diunduh dari: http//www.Ire_kmpk.ugm.ac.id. 